\title{
Models of Growth and Maturity for North Sea Cod
}

\author{
R. M. Cook, P. A. Kunzlik, J. R. G. Hislop, and D. Poulding \\ FRS Marine Laboratory, P. O. Box 101 Victoria Road \\ Aberdeen AB 11 9DB, UK-Scotland
}

\begin{abstract}
Although North Sea cod do not show the large changes in growth and maturity seen in other North Atlantic cod stocks, there are systematic changes which may affect routine assessments. Using weight-at-age data from annual ICES assessments and the International Bottom Trawl Survey (IBTS), a descriptive model which explains weight-at-age in terms of a conventional von Bertalanffy curve and a year-class effect is developed. The fitted year-class effects are correlated with stock biomass indicating a density dependent effect. IBTS maturity data are examined which show that the proportion of fish mature at age is a function both of weight and age. A life history model is constructed which can explain the qualitative changes in maturity in terms of an optimal age of maturity given expectations of growth and natural mortality. A descriptive model based on age and weight is used to reconstruct the historical series of maturity ogives where no direct observations are available. Using the derived maturities, new spawning stock size estimates are calculated and compared with the conventional assessment. In general, taking into account the changes in growth and maturity for North Sea cod does not appear to substantially alter the estimates of sustainable exploitation rates for the stock.
\end{abstract}

Key words: Atlantic Ocean, models, cod, growth, maturity, North Sea

\section{Introduction}

Growth and maturity are two fundamental biological characteristics used in stock assessment. They are essential for the calculation of basic quantities such as spawning stock biomass and equilibrium yield as well as biological reference points including $F_{\max }, F_{0.1}$ and $F_{\text {med }}$. While growth and maturity tend to be characteristic for a species or stock, they nevertheless exhibit annual variation and in the case of some Atlantic cod (Gadus morhua) stocks this variation can be very large. For example in the case of Icelandic cod, between the years 1977-97 the proportion mature at age six varied in the range $22-85 \%$ while mean weight at the same age varied between 2 900-4 200 grams (ICES, MS 1997a). Clearly, with such a large variation, the point estimates of the biological quantities used can have a profound effect on any stock assessment calculation and need to be taken into account (Helser and Brodziak, 1998).

Growth and maturity are clearly related. Stearns and Crandall (1983) describe a life history model which can explain both age and size of maturity based on rate of growth and natural mortality. Given that growth will be affected by a variety of biotic and abiotic factors such as food availability and temperature, it is likely that maturity will also vary in response to these factors. Changes of this nature need to be adequately modelled in assessments if their effects are large.

Recently concern has been expressed about the state of the North Sea cod stock (ICES, 1996; Cook et al., 1997) because in recent years the observed fishing mortality rate has exceeded $F_{\text {crash }}$, the fishing mortality rate calculated to be sufficient to cause the stock to collapse (Cook, 1998). This is illustrated in Fig. 1 which shows the calculated equilibrium spawning stock biomass expected at different fishing mortality rates. The zero equilibrium value corresponds to $F_{\text {crash }}$. The observed annual observations of spawning stock biomass track the expected equilibrium values.

The calculation of $F_{\text {crash }}$ is dependent on estimates of growth and maturity which are usually assumed to be constant. If in fact these biological characteristics vary, then the estimate of $F_{\text {crash }}$ will be affected. Thus there is a need to examine the sensitivity of $F_{\text {crash }}$ to changes in growth and maturity.

The North Sea cod stock is assessed annually by the International Council for the Exploration of 


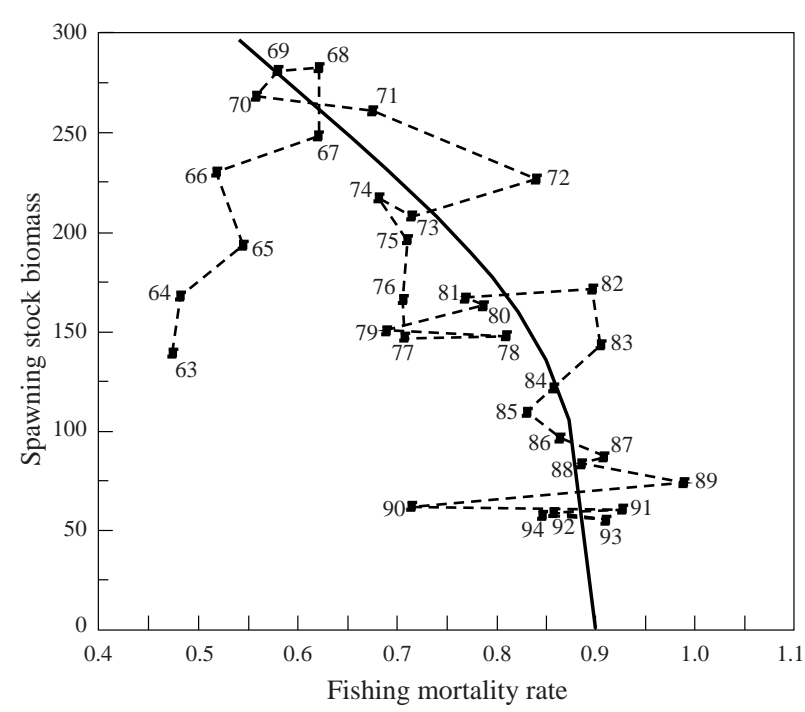

Fig. 1. Equilibrium spawning stock biomass (SSB) plotted against fishing mortality rate, plotted after Cook et al. (1997). The broken lines join the annual observed values of SSB from 196394. The intersection of the equilibrium curve with the $x$ axis is a measure of $F_{c r a s h}$, the fishing mortality expected to produce a stock collapse.

the Sea (ICES) (e.g. ICES, MS 1997b). For all assessments a constant maturity ogive is used. In recent years an ICES co-ordinated survey, the International Bottom Trawl Survey (IBTS) has collected data on maturity for a number of common commercial species, including cod. These data provide an opportunity to examine the variability of maturity and investigate whether any systematic changes are evident, and in particular, whether these are related to growth.

It is generally assumed that, although there are minor changes, the growth rate of North Sea cod is relatively constant (Daan, 1978). Annual estimates of weight-at-age in the stock are routinely given in ICES assessment reports (e.g. ICES, MS 1997b) and these do show some variability. This paper re-examines changes in weight-at-age to see if growth can be related to stock biomass and maturity and whether these changes are likely to be important in assessment calculations.

\section{Models}

\section{a) Weight-at-age}

Weight-at-age, $w$, is commonly modelled using a von Bertalanffy growth function. In the analysis performed here a generalized and re-parameterized version due to Schnute and Fournier (1980) is used i.e.:

$$
w_{i}=w_{1}+\left(w_{A}-w_{1}\right)\left(\frac{1-k^{i-1}}{1-k^{A-1}}\right)^{c} i=1, \ldots . ., A
$$

where $i$ indexes age and $k$ and $c$ are parameters. In this formulation $w_{1}$ and $w_{A}$ are model parameters corresponding to the weight at the youngest and oldest observed ages in the data. This function will predict constant weights at age whereas we seek a model which may explain variable weight-at-age. Jones (1983) noted that cohorts which are large when young tend to retain their higher than average weight throughout their lives. This might be modelled as a cohort specific effect, $g$. Thus the weight-at-age $i$ in year $j$ can be expressed as:

$$
\begin{gathered}
w_{i, j}=g_{j-i+A}\left[w_{1}+\left(w_{A}-w_{1}\right)\left(\frac{1-k^{i-1}}{1-k^{A-1}}\right)^{c}\right] \\
i=1, . . A ; j=1, . . Y
\end{gathered}
$$

Given a set of observed weights-at-age, $w^{\prime}$, the estimation of the model parameters can be achieved, assuming lognormal errors, by minimising the sum of squares:

$$
\sum_{i=1}^{M} \sum_{j=1}^{Y}\left(\log \left(w^{\prime} i, j\right)-\log \left(w_{i, j}\right)\right)^{2}
$$

\section{b) Maturity-at-age}

Typically, in the assessments of North Sea cod, maturity is assumed to be age dependent (ICES, MS $1997 b)$. The proportion of fish mature, $p$, increases with age and may be approximated by a logistic function of the type;

$$
p_{i}=\left(\frac{e^{a_{0}+a_{1} i}}{1-e^{a_{0}+a_{1} i}}\right)
$$

where $a_{0}$ and $a_{1}$ are parameters. It is probably more realistic to assume that the time at which a fish matures is dependent both on age and size (Stearns and Crandall, 1983). Inspection of data on maturity for North Sea cod (see below) suggested that within an age class, the rate at which fish matured was size dependent. The dependence of maturity on size, however, appears to be age specific. With a logit transformation of equation (4), a simple linear model which incorporates such effects may be written: 


$$
\begin{gathered}
\log \left(\frac{p_{i, j}}{1-p_{i, j}}\right)=a_{0}+a_{1} i+b_{i} w_{i, j} \\
i=1, \ldots A ; j=1, \ldots Y
\end{gathered}
$$

With appropriate data on the proportions of fish mature-at-age and weight-at-age, it is possible to estimate the parameters $a$ and $b$ by ordinary least squares, assuming normal errors.

\section{c) Life history model}

In common with many other fish, cod grow throughout their lives. The larger an individual fish becomes, the less vulnerable it is to predation and it may carry a larger number of eggs. The rate of growth will depend on the relative investment of surplus energy into growth or reproduction. As more energy is invested in reproduction, somatic growth rate will slow down. Early maturation will result in fish of a smaller size at age with concomitant smaller egg capacity and higher vulnerability to predation. However, early maturation means that there is a greater chance of spawning during the individual's lifetime. The optimum time of spawning is therefore a trade off between maximizing size, to produce more eggs, against the risk of an early death while still immature. Models based on these ideas are well known (e.g. Emlen, 1973; Charlesworth, 1980; Stearns and Crandall, 1983; Ware, 1983; Myers and Doyle, 1983).

For exploratory purposes a model is developed here which examines maturation strategies which maximize the expected egg production over an individual life time. Using the formulation of Myers and Doyle (1983) surplus energy, $f\left(w_{i}\right)$, produced at age $i$ is given by:

$$
f\left(w_{i}\right)=\alpha w_{i}{ }^{\beta}
$$

If the proportion of energy which goes into reproduction is $u_{i}$, and $v$ is the age of maturity then growth can be modelled as:

$$
w_{i+1}=w_{i}+\left(1-p_{i} u_{i}\right) f\left(w_{i}\right) \mid \begin{aligned}
& p_{i}=0 ; i<v \\
& p_{i}=1 ; i \geq v
\end{aligned}
$$

Similarly the corresponding production of eggs will be proportional to $p_{i} u_{i} f\left(w_{i}\right)$ and will be a measure of fecundity at age. If the survival of fish to age $i$ is $n_{i}$ then the total egg production of an individual will be proportional to:

$$
\sum_{i=1}^{\infty} n_{i} p_{i} u_{i} f\left(w_{i}\right) \mid \begin{aligned}
& p_{i}=0 ; i<v \\
& p_{i}=1 ; i \geq v
\end{aligned}
$$

In the absence of fishing, the survival rate will depend only on natural mortality, $M$ and in particular;

$$
n_{i}=\exp \left(-\sum_{i=1}^{A-1} M_{i}\right)
$$

Estimates of natural mortality for cod in the North Sea are provided by ICES (MS 1997b) and decline with age. On the assumption that natural mortality is primarily due to predation and is therefore likely to be size dependent, the change in natural mortality with size can be modelled as:

$$
M_{i}=m_{0} e^{-m_{l} w_{i}}+m_{2}
$$

where $m_{0}, m_{1}$ and $m_{2}$ are equation constants.

The overall objective is now to find an age of maturity, $v$, which maximizes expression (8).

\section{Data and Methods}

Basic weight-at-age data are taken from ICES (MS 1997b) (Table 1). This report contains estimates of weight-at-age in the stock which are essentially estimates of mean weight in the catch based on market sampling. The mean weights of fish at the youngest ages are therefore likely to suffer from positive bias. However, most of the analysis in this paper considers mature fish, which involves age groups largely unaffected by such bias. The weight model was fitted to data for the years 197495 and the year-class effect estimated. This was then correlated with estimates of total stock biomass given in ICES (MS 1997b).

Data on maturity are routinely collected as part of the ICES co-ordinated International Bottom Trawl Survey (IBTS) of the North Sea in the first quarter of the year. Estimates of the proportion of fish mature at age for both sexes combined (Table 2) were obtained from Poulding (MS 1997). These estimates were obtained from data supplied by the ICES Secretariat from the IBTS database. Equation (5) was fitted to the maturity data in Table 2 with the weight data in Table 1 as an explanatory variable. This provided a relationship linking maturity to weight-at-age in the stock. Using this relationship estimates of maturity were made for the years 1974-79 in which no measurements of maturity were available. The data and model provide estimates of maturity up to age 6 . For older ages it was assumed that all fish were mature. The predicted 
TABLE 1. North Sea Cod Stock Weights (kg)

\begin{tabular}{|c|c|c|c|c|c|c|}
\hline \multirow[b]{2}{*}{ Year } & \multicolumn{6}{|c|}{ Age } \\
\hline & 1 & 2 & 3 & 4 & 5 & 6 \\
\hline \multicolumn{7}{|c|}{ a) Market sampling data } \\
\hline 1974 & 0.594 & 1.039 & 2.217 & 4.156 & 6.174 & 8.333 \\
\hline 1975 & 0.619 & 0.899 & 2.348 & 4.226 & 6.404 & 8.691 \\
\hline 1976 & 0.568 & 1.029 & 2.470 & 4.577 & 6.494 & 8.620 \\
\hline 1977 & 0.542 & 0.948 & 2.160 & 4.607 & 6.713 & 8.828 \\
\hline 1978 & 0.572 & 0.937 & 2.001 & 4.146 & 6.531 & 8.667 \\
\hline 1979 & 0.550 & 0.936 & 2.411 & 4.423 & 6.580 & 8.475 \\
\hline 1980 & 0.550 & 1.003 & 1.948 & 4.401 & 6.109 & 9.120 \\
\hline 1981 & 0.723 & 0.837 & 2.189 & 4.615 & 7.045 & 8.884 \\
\hline 1982 & 0.589 & 0.962 & 1.858 & 4.130 & 6.784 & 8.903 \\
\hline 1983 & 0.632 & 0.919 & 1.835 & 3.880 & 6.491 & 8.423 \\
\hline 1984 & 0.594 & 1.007 & 2.156 & 3.972 & 6.190 & 8.362 \\
\hline 1985 & 0.589 & 0.932 & 2.135 & 4.161 & 6.310 & 8.404 \\
\hline 1986 & 0.576 & 0.886 & 1.836 & 3.538 & 6.188 & 8.071 \\
\hline 1987 & 0.626 & 0.963 & 1.931 & 3.614 & 5.983 & 8.241 \\
\hline 1988 & 0.574 & 0.867 & 1.939 & 3.175 & 5.859 & 7.844 \\
\hline 1989 & 0.669 & 1.057 & 1.819 & 3.549 & 5.250 & 7.818 \\
\hline 1990 & 0.737 & 0.976 & 2.174 & 3.795 & 5.903 & 7.867 \\
\hline 1991 & 0.668 & 1.078 & 2.040 & 3.987 & 6.071 & 7.986 \\
\hline 1992 & 0.699 & 1.143 & 2.543 & 4.223 & 6.239 & 8.465 \\
\hline 1993 & 0.696 & 1.063 & 2.472 & 4.545 & 6.523 & 8.065 \\
\hline 1994 & 0.673 & 1.074 & 2.201 & 4.469 & 7.144 & 8.422 \\
\hline 1995 & 0.718 & 1.021 & 2.204 & 4.289 & 7.215 & 8.966 \\
\hline
\end{tabular}

\begin{tabular}{lllllr}
\multicolumn{5}{c}{ b) Research vessel data } \\
1980 & 0.14 & 0.60 & 1.47 & 3.63 & 6.71 \\
1981 & 0.11 & 0.38 & 1.49 & 3.77 & 6.03 \\
1982 & 0.14 & 0.56 & 1.34 & 3.75 & 6.4 \\
1983 & 0.10 & 0.72 & 1.71 & 3.74 & 6.42 \\
1984 & 0.14 & 0.41 & 1.59 & 2.77 & 5.37 \\
1985 & 0.07 & 0.44 & 1.49 & 3.39 & 4.86 \\
1986 & 0.08 & 0.46 & 1.38 & 2.96 & 4.85 \\
1987 & 0.11 & 0.43 & 0.82 & 3.46 & 4.83 \\
1988 & 0.09 & 0.45 & 1.55 & 2.88 & 5.8 \\
1989 & 0.09 & 0.58 & 1.20 & 3.16 & 4.45 \\
1990 & 0.09 & 0.46 & 1.79 & 3.47 & 5.93 \\
1991 & 0.08 & 0.55 & 1.61 & 3.00 & 5.46 \\
1992 & 0.10 & 0.70 & 1.96 & 4.23 & 6.29 \\
1993 & 0.05 & 0.47 & 1.86 & 4.10 & 6.24 \\
1994 & 0.06 & 0.40 & 1.32 & 3.75 & 6.52 \\
1995 & 0.07 & 0.40 & 1.15 & 3.33 & 5.38 \\
\hline
\end{tabular}

maturities for all years were then used to reconstruct estimates of the historical time series of spawning stock biomass. The revised SSB values were then used to calculate $F_{c r a s h}$ and $F_{\text {med, }}$, which were compared to the values based on conventional data. In the analysis, $F_{\text {crash }}$ was calculated using the methodology described in Cook (1998).
In addition to the market sampling weights, weights-at-age obtained from the IBTS survey were also used (Table 1). These data will be free of some of the biasses associated with weights of commercially caught fish. As a check on the relationship established between maturity and weights described above which may be biassed, equation (5) was fitted to the research vessel weight data. Because the time series of data available is short, this relationship could not be used to generate maturity ogives for the years 1975-79.

In order to explore the behaviour of the life history model, parameter estimates of the surplus energy function were taken from Myers and Doyle (1983). Estimates of the parameters in equation (10) were obtained by an ordinary least squares regression of natural mortality-at-age (given in ICES, MS 1997b) on mean weight-at-age. In the regression the value of $m_{2}$ was fixed at 0.2 . The value of $u_{i}$ was arbitrarily taken as 0.7 . The value was chosen because it gave the closest correspondence between predicted and observed mean weights-at-age when the age of maturity is four, close to the observed value. The parameter estimates are given in Table 3.

Given the parameter estimates in Table 3, equation (8) can be maximized with respect to $v$, the age of maturity. This will give a unique age of maturity of an individual fish or a group of identical fish. In order to simulate the population effects on the proportion of fish mature at any age, the nominal parameter values were randomized to simulate different growth strategies and different expectations of survival. This was done by assigning a variance to each parameter and drawing a random value from a normal distribution with the nominal value as the mean. Two hundred individual strategies were set up in this way and the optimal age of maturity determined. Subsamples of 20 were then taken from these to obtain mean weights-at-age and the corresponding proportion mature-at-age. Subsampling in this way is analogous to the way sampling is done to obtain real estimates of maturity ogives.

\section{Results}

The year-class effects and growth parameters estimated for the weight-at-age data are given in Table 4. Inspection of the year-class effects shows that they change gradually from year to year suggesting they may be autocorrelated. However, the 
TABLE 2. Cod maturity data from IBTS, both sexes combined.

\begin{tabular}{lccccccc}
\hline \hline & \multicolumn{7}{c}{ Age } \\
\cline { 2 - 7 } Year & 1 & 2 & 3 & 4 & 5 & 6 & Sample Size \\
\hline 1980 & 0.01 & 0.10 & 0.08 & 0.56 & 1.00 & 0.88 & 1011 \\
1981 & 0.01 & 0.04 & 0.16 & 0.52 & 0.85 & 0.87 & 2422 \\
1982 & 0.00 & 0.03 & 0.17 & 0.64 & 0.93 & 1.00 & 2185 \\
1983 & 0.00 & 0.03 & 0.20 & 0.50 & 0.96 & 0.99 & 2681 \\
1983 & 0.00 & 0.06 & 0.25 & 0.42 & 0.81 & 0.98 & 1222 \\
1985 & 0.00 & 0.04 & 0.10 & 0.45 & 0.56 & 0.91 & 2095 \\
1986 & 0.00 & 0.09 & 0.18 & 0.35 & 0.63 & 0.90 & 4551 \\
1987 & 0.00 & 0.02 & 0.15 & 0.60 & 0.76 & 0.98 & 4866 \\
1988 & 0.00 & 0.05 & 0.27 & 0.53 & 0.90 & 0.95 & 3045 \\
1989 & 0.00 & 0.13 & 0.24 & 0.59 & 0.77 & 0.97 & 3390 \\
1990 & 0.01 & 0.19 & 0.54 & 0.73 & 0.93 & 0.99 & 2290 \\
1991 & 0.00 & 0.09 & 0.39 & 0.50 & 0.89 & 0.98 & 1295 \\
1992 & 0.00 & 0.21 & 0.52 & 0.85 & 0.85 & 1.00 & 1435 \\
1993 & 0.00 & 0.07 & 0.42 & 0.70 & 0.88 & 0.96 & 1978 \\
1994 & 0.00 & 0.14 & 0.43 & 0.77 & 0.98 & 1.00 & 1684 \\
1995 & 0.01 & 0.05 & 0.30 & 0.82 & 1.00 & 0.97 & 2559 \\
\hline
\end{tabular}

TABLE 3. Parameters used in life history model and $\mathrm{CV}$ s used to generate simulated population.

\begin{tabular}{lrc}
\hline \hline Parameter & value & $\mathrm{CV}$ \\
\hline $\mathrm{m}_{0}$ & 7.86 & 0.10 \\
$\mathrm{~m}_{1}$ & 3.60 & 0.10 \\
$\mathrm{~m}_{2}$ & 0.20 & 0.10 \\
$\mathrm{w}_{1}$ & 0.70 & 0.30 \\
$\alpha$ & 40.00 & 0.01 \\
$\beta$ & 0.51 & 0.01 \\
$\mathrm{u}$ & 0.70 & 0.00 \\
\hline
\end{tabular}

standard deviations of the parameter estimates is such as to suggest the year-class effects do not differ significantly from each other. Thus one may not conclude that there is a unique size effect for each cohort. Figure 2 shows the year-class effects plotted against total stock size. Here stock biomass is measured in the year the year-class was age 1 . There is a strong indication of a negative relationship with a significant linear correlation coefficient $(r=0.51$; $0.05>p>0.01)$. This provides some evidence that growth may be density dependent.

Figure 3 shows the maturity data plotted against mean weight-at-age. The typical pattern of increasing maturity with age can be seen. In addition it appears from inspection that within an age group maturity increases with size. It does not appear that maturity can be explained by size or age alone. The results of fitting the maturity model to the data are given in Table 5 and Fig. 3. With the exception of the two oldest ages, the slopes associated with both age and size are significant. The age specific effects of size appear to decrease with age. However, only some of these slopes are significantly different.

Figure 4 shows the relationship between maturity and weight when research vessel weight data are used. The results are qualitatively similar to Fig. 3 , indicating that the changes of slope with age are unlikely to be an artifact caused by biassed data. Table 5 shows the estimated model parameters. The standard deviations of the parameters are substantially larger than with the market sampling weights and results from the very much smaller sample sizes used to calculate mean weight-at-age in the research vessel data.

The results of the simulation experiment using the life history model are shown in Fig. 5. The realization shown illustrates some of the features seen in the real data in Fig. 3 and 4. It can be seen that the proportion of fish mature is both size and age dependent, with a tendency for maturity to increase rapidly with size at a given age. The simulations do not provide strong evidence of decreasing size dependent slopes with age, however. 
TABLE 4. Parameters estimated when fitting the growth model to stock weight data.

\begin{tabular}{lcc}
\hline \hline Year & Year-class effect & s.d. \\
\hline 1967 & 0.0785 & 0.0739 \\
1968 & 0.0774 & 0.0697 \\
1969 & 0.0758 & 0.0676 \\
1970 & 0.1097 & 0.0663 \\
1971 & 0.1213 & 0.0655 \\
1972 & 0.1323 & 0.0649 \\
1973 & 0.1635 & 0.0645 \\
1974 & 0.1253 & 0.0641 \\
1975 & 0.1412 & 0.0638 \\
1976 & 0.1164 & 0.0638 \\
1977 & 0.1332 & 0.0638 \\
1978 & 0.1336 & 0.0638 \\
1979 & 0.1150 & 0.0638 \\
1980 & 0.0740 & 0.0638 \\
1981 & 0.1189 & 0.0638 \\
1982 & 0.0922 & 0.0638 \\
1983 & 0.0888 & 0.0638 \\
1984 & 0.0525 & 0.0638 \\
1985 & 0.0224 & 0.0638 \\
1986 & 0.0440 & 0.0638 \\
1987 & 0.0656 & 0.0638 \\
1988 & 0.1081 & 0.0643 \\
1989 & 0.1395 & 0.0648 \\
1990 & 0.2481 & 0.0654 \\
1991 & 0.2435 & 0.0662 \\
1992 & 0.1921 & 0.0672 \\
1993 & 0.2038 & 0.0686 \\
1994 & 0.2009 & 0.0708 \\
1995 & 0.2640 & 0.03751 \\
$w_{1}$ & & \\
$w_{A}$ & 0.0346 \\
$c$ & & \\
\hline
\end{tabular}

Figure 6 shows the spawning stock biomass recalculated using the predicted maturity ogive based on the fitted model and observed stock weights. For comparison the spawning biomasses using the conventional maturity ogive are shown. Although there are variations in weight leading to a variable ogive over time, the effect of the fitted ogive is mainly to re-scale the SSBs to higher value. This arises mainly because the ogive from the IBTS data generally shows higher proportions mature at younger ages than the conventional ogive and results in SSBs which are about 10-15\% larger.

The revised maturity data make very little difference to the calculated $\mathrm{F}$ reference points. The

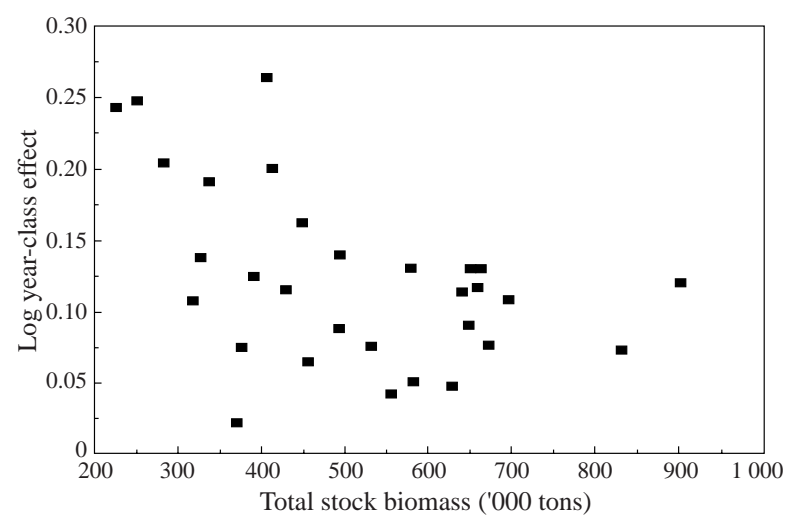

Fig. 2. The $\log$ year-class effects estimated after fitting the growth model to cod stock weight data plotted against total stock biomass in the year the cohort was age 1 . The linear correlation coefficient, $r=0.51, p<0.05$.

revised estimate of $F_{\text {crash }}$ is 0.88 compared with the conventional value of 0.89 . The value of $F_{\text {med }}$ is unchanged at 0.82

\section{Discussion}

Weights-at-age for North Sea cod do not show a large amount of inter-annual variability. The coefficient of variation ranges between 5-10\% depending on age. In recent years there has been an increase in weight-at-age and this is seen as an increase in the year-class effect for the more recent cohorts (Table 4). The increase is associated with a decline in the total stock and spawning stock biomasses. It is quite likely that this link is causal through competition resulting in density dependent growth.

There is good reason on the basis of recent maturity data to believe that the age of maturity is affected by growth rate. Furthermore, maturity appears to be related both to age and size. When the maturity model was fitted to the observed data the slopes associated with age and weight were significantly different from zero. There is some evidence that the rate of change of maturity with size is age dependent. At younger ages fish mature more rapidly with size than at older ages.

The observed changes in maturity with age and size are explicable in terms of a model which maximizes egg production over an individual life time. The optimum age of maturity in the model is a trade 


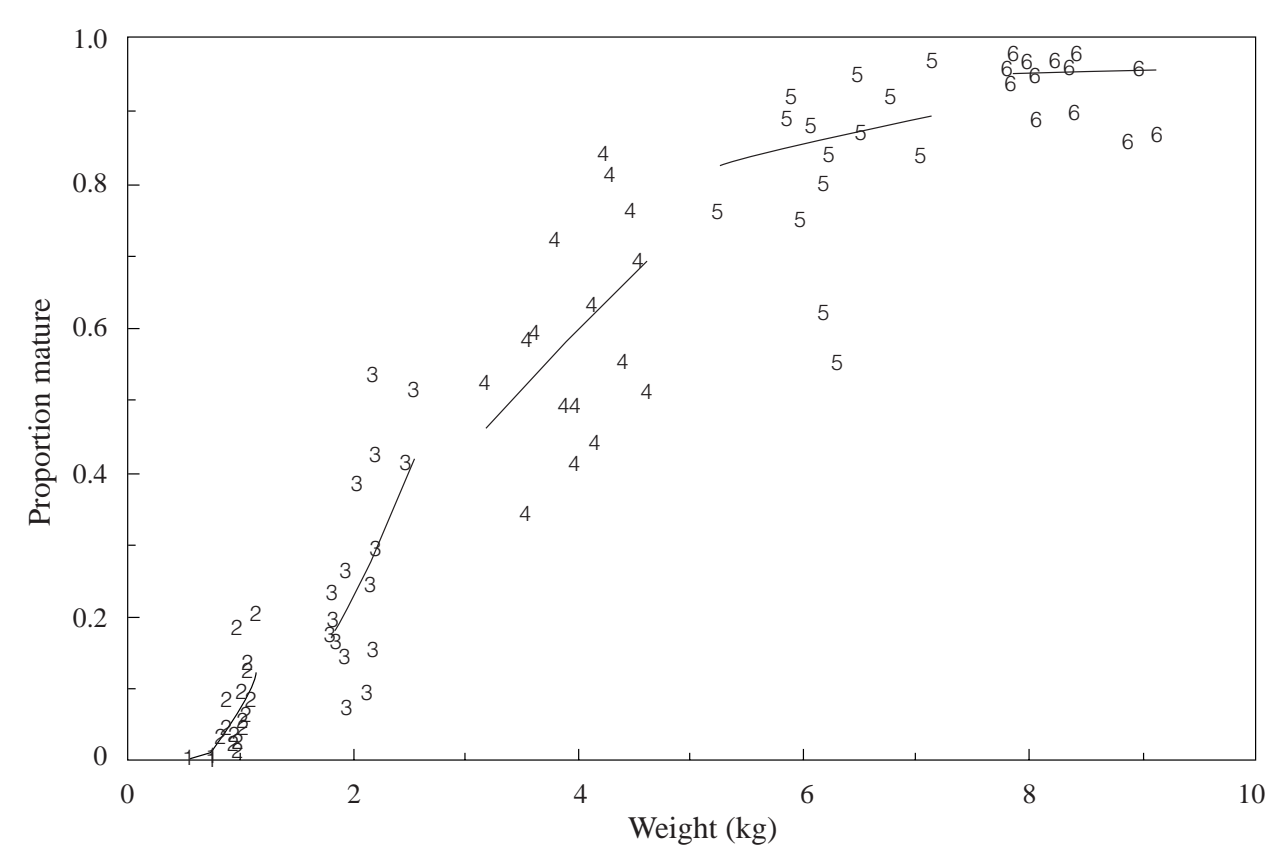

Fig. 3. Proportion mature-at-age plotted against market sample mean weight-at-age. The numeric labels indicate the ages. The lines show the fitted proportions mature estimated from the model.

TABLE 5. Parameters estimated when fitting the maturity model.

\begin{tabular}{cccccc}
\hline \hline & \multicolumn{2}{c}{$\begin{array}{c}\text { Using Market } \\
\text { Sampling Weights }\end{array}$} & s.d. & & \multicolumn{2}{c}{$\begin{array}{c}\text { Using Research } \\
\text { Vessel Weights }\end{array}$} \\
\cline { 2 - 3 } \cline { 5 - 6 } Parameter & value & 2.6888 & & value & s.d. \\
\hline $\mathrm{a}_{0}$ & -11.1806 & 0.7482 & & -3.6459 & 1.2072 \\
$\mathrm{a}_{1}$ & 2.2174 & 2.9627 & -9.2776 & 8.3406 \\
$\mathrm{~b}_{1}$ & 6.3252 & 1.4265 & 1.8074 & 1.1124 \\
$\mathrm{~b}_{2}$ & 4.1995 & 0.4899 & 1.5878 & 0.3329 \\
$\mathrm{~b}_{3}$ & 1.6579 & 0.2732 & 1.1044 & 0.2048 \\
$\mathrm{~b}_{4}$ & 0.6820 & 0.2514 & 0.9251 & 0.1831 \\
$\mathrm{~b}_{5}$ & 0.3203 & 0.2667 & $\mathrm{n} / \mathrm{a}$ & $\mathrm{n} / \mathrm{a}$ \\
$\mathrm{b}_{6}$ & 0.1337 & & & & \\
\hline
\end{tabular}

off between the need to delay maturity, grow fast, and produce more eggs against the need to mature early and spawn before dying young. While one might expect egg maximization to result from natural selection, it is not a sufficient condition for an evolutionarily stable strategy (ESS) (Maynard Smith, 1972). This requires the maximisation of the population intrinsic rate of increase. Evaluating such a strategy would require more information on the conversion of surplus energy into eggs and has not been attempted here.
Revised estimates of spawning stock biomass based on the new maturity data alter the scale of the SSB values without making any substantial change to the trajectory over time. In general the revised estimates are about $10 \%$ larger than those based on a constant maturity ogive. Since estimates of recruitment are unaffected by the analysis this means that the observed cod recruitment has been produced by larger SSBs than was previously thought. However, although such a change revises the estimate of the slope of the stock-recruitment 


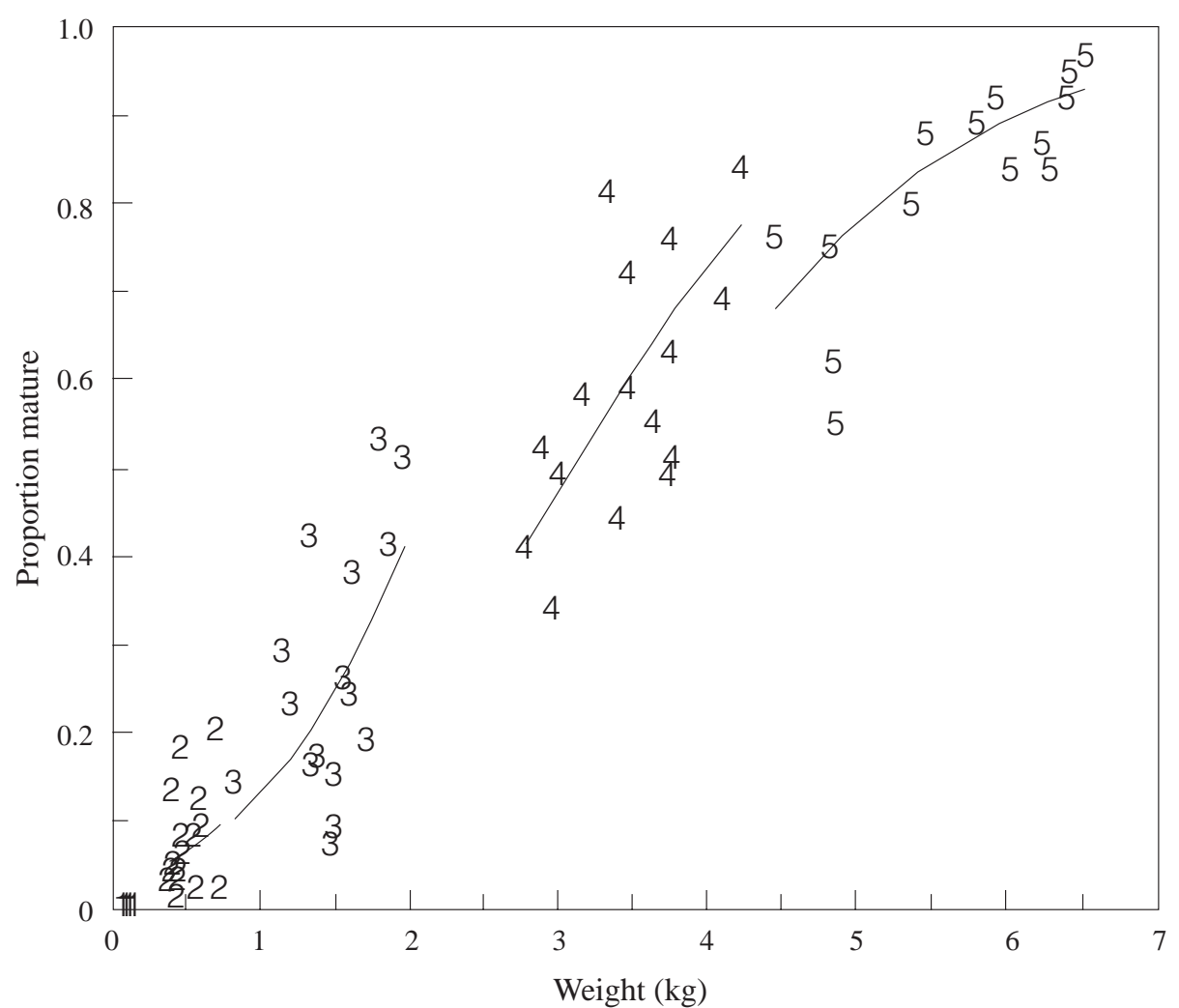

Fig. 4. Proportion mature-at-age plotted against research vessel mean weight-at-age. The numeric labels indicate the ages. The lines show the fitted proportions estimated from the model.

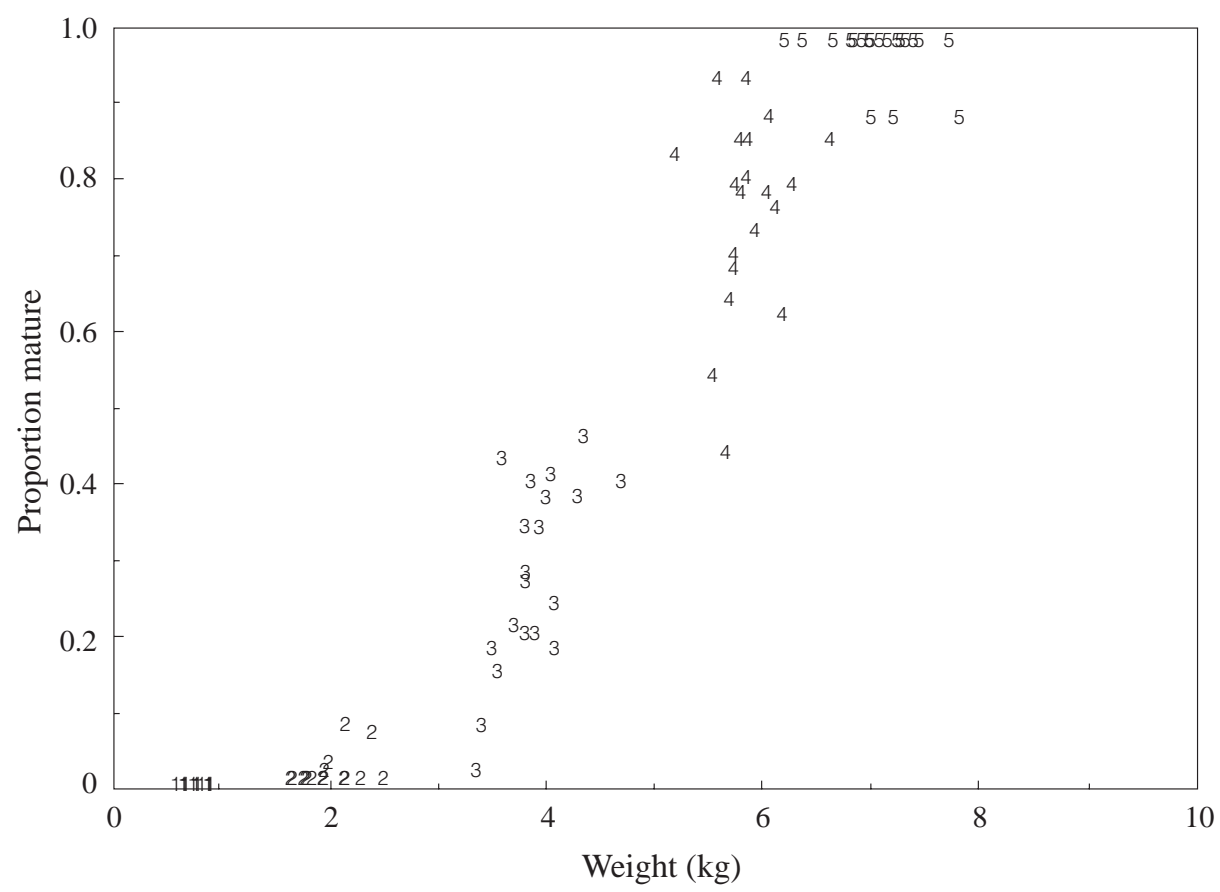

Fig. 5. Results of a simulation experiment using the life history model predicting optimal age of maturity. The proportion of fish mature-at-age/weight are the results from a population with variable growth rates and expectations of natural mortality. Numeric labels indicate age. 


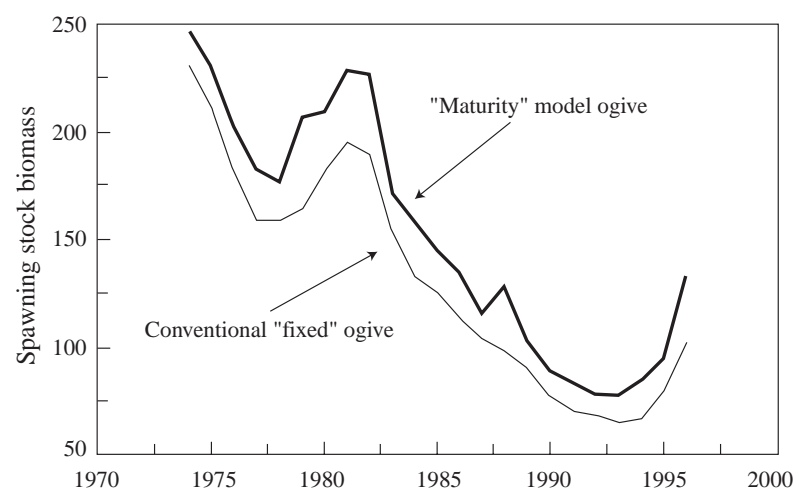

Fig. 6. Spawning stock biomass estimated using the maturity model to reconstruct historical maturity ogives and using the conventional maturity ogive in ICES (MS 1997b).

function at the origin it makes little or no difference to biological reference points such as $F_{\text {crash }}$ and $F_{\text {med }}$. This is because although the steepness of the slope changes, it is compensated for in the calculation of the $F$ values by a decrease in the average age of first maturity. Overall, therefore, for North Sea cod, including the effect of density dependent growth and adopting more realistic maturity data do not make a significant difference to the calculation of certain critical reference points.

\section{References}

CHARLESWORTH, B. 1980. Evolution in age-structured populations. Cambridge University Press, Cambridge.

COOK, R. M., A. SINCLAIR, and G. STEFÀNSSON. 1997. Potential collapse of North Sea cod stocks. Nature, 385: 521-522.

COOK, R. M. 1998. A sustainability criterion for the exploitation of North Sea cod. ICES J. Mar. Sci., 55:
1061-1070.

DAAN, N. 1978. Changes in cod stocks and cod fisheries in the North Sea. ICES Rapp. Proc.-verb., 172: 39-57.

EMLEN, J. M. 1973. Ecology: An evolutionary approach. Addison-Wesley, Reading Mass.

HELSER, T. E., and J. K. T. BRODZIAK. 1998. Impacts of density dependent growth and maturation on assessment advice to rebuild depleted U.S. silver hake (Merluccius bilinearis) stock. Can. J. Fish. Aquat. Sci., 55: 882-892.

ICES. 1996. Report of the ICES Advisory Committee on Fishery Management, 1995. ICES Coop. Res. Rep., No. 214.

MS 1997a. Report of the Northwestern working group. ICES C.M. Doc., No. Assess: 13.

MS 1997b. Report of the working group on the assessment of demersal stocks in the North Sea and Skagerrak. ICES C.M. Doc., No. Assess:6.

JONES, R. 1983. An investigation of North Sea haddock (Melanogrammus aeglefinus) length-at-age data, with particular reference to the effects on growth of the outstanding year-classes of 1962 and 1967. ICES J. Cons., 41: 50-62.

MAYNARD SMITH, J. 1972. On Evolution. Edinburgh University Press, Edinburgh.

MYERS, R. A., and R. W. DOYLE. 1983. Predicting natural mortality rates and reproduction-mortality trade-offs from fish life history data. Can. J. Fish. Aquat. Sci., 40: 612-620.

POULDING, D. MS 1997. Unpublished MSc thesis, University of Aberdeen, Scotland.

SCHNUTE, J., and D. FOURNIER. 1980. A new approach to length-frequency analysis: growth structure. Can. J. Fish. Aquat. Sci., 37: 1337-1351.

STEARNS, S. C., and R. E. CRANDALL. 1983. Plasticity for age and size at sexual maturity: A life-history response to unavoidable stress. In: Fish reproduction: strategies and tactics. Potts, G. W., and R. J. Wooton (eds). Academic press, London, p. 13-33.

WARE, D. M. 1983. Fitness of different reproductive strategies in teleost fishes. In: Fish reproduction: strategies and tactics, Potts, G. W., and R. J Wooton (eds). Academic press, London, p. 349-366. 